\title{
Bioactive potential of Diadema sp. from the South East coast of Mauritius
}

\author{
Lisa Karen Yee Chin Youne Ah Shee Tee, Daneshwar Puchooa*, Vishwakalyan Bhoyroo \\ Department of Agricultural \& Food Science, Faculty of Agriculture, University of Mauritius, Réduit, Mauritius.
}

\begin{tabular}{|c|c|}
\hline ARTICLE INFO & ABSTRACT \\
\hline $\begin{array}{l}\text { Article history: } \\
\text { Received on: August 16, } 2017 \\
\text { Accepted on: September } 22,2017 \\
\text { Available online: November } 09,2017\end{array}$ & $\begin{array}{l}\text { As a consequence of the alarming rise in antimicrobial resistance, this study aimed at evaluating the bioactive } \\
\text { potential of sea urchin extract, Diadema sp. Two different tissues; shells and gonads were used and two drying } \\
\text { methods were compared; freeze-drying (FD) and non-FD (NFD). Statistically, significant interaction was observed } \\
\text { between the drying methods and solvents used. Compared to the gonadal tissue, NFD methanolic shell extract }\end{array}$ \\
\hline $\begin{array}{l}\text { Key words: } \\
\text { Sea urchin, } \\
\text { Antibacterial activity, } \\
\text { Scavenging capacity, } \\
\text { Larvicidal activity }\end{array}$ & $\begin{array}{l}\text { reported higher extraction yield, } 9.13 \pm 0.87 \% \text {. Phenolic content assessed using the Folin-Ciocalteu method was } \\
\text { higher in NFD gonadal extract, } 688.1 \mathrm{mg} \text { gallic acid equivalents/g distilled water. Promising antimicrobial activity } \\
\text { was recorded using agar disc diffusion and results confirmed using minimum inhibitory concentration. Among the } \\
\text { bacteria used, Escherichia coli and Staphylococcus aureus were more vulnerable, reporting inhibition zone of } 16.3 \\
\pm 1.37 \mathrm{~mm} \text { and } 17.1 \pm 0.23 \mathrm{~mm} \text { using NFDSM and FDGM extract, respectively. DPPH antioxidant assay showed } \\
\text { NFDSM having better activity than the positive control, half maximal inhibitory concentration of } 3.77 \mu \mathrm{g} / \mathrm{ml} \text {. No } \\
\text { significant larvicidal activity was recorded. Diadema sp. are a potential source of novel antimicrobial compounds } \\
\text { and suggest its possible use as natural food-grade antioxidant. This study also shows NFD method and methanol as } \\
\text { the recommended solvent for maximal bioactivity. }\end{array}$ \\
\hline
\end{tabular}

\section{INTRODUCTION}

Sea urchins are constantly surrounded by a microbial population that can be as high as $10^{6}$ to $10^{9} \mathrm{ml}$ [1]. Yet, they have survived over 200 years [2], indicating their strong bioactive potential. The aim of this study was to investigate their bioactive potency and the impacts of different drying methods on such activities. Secondary metabolites are largely influenced by the extraction solvents and drying methods used. It was first hypothesized that the destructive nature of freeze-drying (FD) process will both conserve the secondary metabolites by limiting the biological activity and increases the extraction yield. Sea urchins are intriguing creatures; the strength of their biological potency is reflected in the color of their spines [3]. Species from Diadema genus, known to be slightly venomous, were used in this study. The shells and spines which are normally discarded after consumption contain different kind of polyhydroxylated naphthoquinones (PHNQs) responsible for the most biological activities [4]. Since organisms belonging to the same phylum share-related developmental and evolutionary resemblance, it was hypothesized that Diadema urchins might also exhibit larvicidal activity.

*Corresponding Author

Daneshwar Puchooa,

Faculty of Agriculture,

University of Mauritius,

Moka, Mauritius

Email: sudeshp@uom.ac.mu

\section{MATERIALS AND METHODS}

\subsection{Sample Collection and Identification}

Samples were collected in the South East coast of Mauritius Island by snorkelling. They were morphologically identified as per [5-7], dissected and stored at $-20^{\circ} \mathrm{C}$ until further analysis.

\subsection{Sample Extraction}

Gonadal and shell extracts were obtained as described by [8], with some slight modifications. $20 \mathrm{~g}$ of FD gonads were homogenized using a mortar and pestle on ice and transferred into a conical flask containing $50 \mathrm{ml}$ of concentrated chloroform in a shaker (135 rpm for 6 days). The mixture was filtered and centrifuged. The supernatant was filtered and extract concentrated using a rotary evaporator at $40^{\circ} \mathrm{C}$, $140 \mathrm{rpm}$. The same procedure was applied using FD shells, non-FD (NFD) samples and using a second solvent, methanol.

\subsection{Total Phenols}

The Folin-Ciocalteu method was used to determine the total phenolic content (TPC) of the extracts. Extracts were prepared to a concentration of $100 \mu \mathrm{g} / \mathrm{ml}$ and transferred to a test tube containing $0.5 \mathrm{ml}$ of distilled water (DW) and $0.25 \mathrm{ml}$ of Folin-Ciocalteau solution. The tubes were vortexed, and after $3 \mathrm{~min}, 1.25 \mathrm{ml}$ of $20 \%$ sodium carbonate solution was added. The tubes were incubated at $40^{\circ} \mathrm{C}$ for $40 \mathrm{~min}$ and absorbance read at $725 \mathrm{~nm}$. The standard curve 
of gallic acid was used to calculate the TPC of extracts as gallic acid equivalents (GAE).

\subsection{Antibacterial Bioassay}

Four bacterial strains were used in this study: Escherichia coli, Acinetobacter spp., Staphylococcus aureus, and Enterococcus spp. Agar disc diffusion was used as preliminary screening and activities were confirmed employing minimum inhibitory concentration (MIC) [9]. Sterile discs of Whatman No.1 filter paper were dipped in $10 \mu \mathrm{l}$ of $100 \mathrm{mg} / \mathrm{ml}$ sea urchin extracts. The plates were inverted and incubated at $37^{\circ} \mathrm{C}$ for $24 \mathrm{~h}$. Inhibition zone was measured using a ruler in $\mathrm{mm}$. Tetracycline was used as positive control while the negative controls used were $70 \%$ methanol and chloroform.

\subsubsection{MIC and minimum bactericidal concentration (MBC)}

Extract showing clear inhibition zone was selected for the determination of MIC and MBC. $100 \mu 1$ extracts were two-fold serially diluted with $100 \mu 1$ Mueller-Hinton Broth. Methanol and chloroform were used as negative control and $10 \mathrm{mg} / \mathrm{ml}$ of chloramphenicol as a positive control. Bacterial inoculums were diluted to a concentration of $10^{6}$ colony-forming units $/ \mathrm{ml}$, and for a clear distinction, $40 \mu 1$ of $0.2 \mathrm{mg} / \mathrm{ml}$ p-iodonitrotetrazolium violet (INT) dye indicator was added to each well.

MBC consisted of sub-culturing from the well showing no microbial growth onto a free antibiotic medium, incubated at $37^{\circ} \mathrm{C}$. Point $\mathrm{MBC}$ was considered only if no bacterial colony was observed [1].

\subsection{Antioxidant Assay}

Antioxidant testing was as described by [10]. $2 \mathrm{ml}$ of $0.16 \mathrm{mM}$ methanolic solution of DPPH was added to a test tube containing $2 \mathrm{ml}$ of an aliquot of extract. The tubes were incubated in the dark, at room temperature for $30 \mathrm{~min}$. Absorbance was read at $517 \mathrm{~nm}$ and scavenging capability of the extract calculated using the formula below.

$$
\text { Scavenging effect }(\%)=\left[1-\frac{\begin{array}{c}
\text { Absorbance of sample }- \\
\text { Absorbance of sample blank }
\end{array}}{\text { Absorbance of control }}\right] \times 100
$$

The control comprised of $2 \mathrm{ml}$ methanol and $2 \mathrm{ml}$ of DPPH methanolic solution and the blank comprised of sample and methanol only. Ascorbic acid was used as a positive control.

\subsection{Larvicidal Assay}

The standard bioassay protocol by [11] was used to assess the larvicidal activity of the extract. The extracts were diluted to a concentration ranging from $0.5 \%$ to $2 \%$ and third instar larvae, $A$. aegypti were exposed to the solution. This bioassay was carried out at room temperature and observation made after 12, 24, 36, and $48 \mathrm{~h}$. Temephos was used as a positive control while water and the solvents only were used as a negative control. The probit scale analysis was used to determine the half maximal inhibitory concentration $\left(\mathrm{IC}_{50}\right)$ values of the extract.

\section{RESULTS AND DISCUSSION}

\subsection{Sample Identification}

By means of its long, black, and slender-like nature of its spines, Diadema species are easily distinguished from other echinoderms [1].
Most species consist of certain morphological traits that soon become faint in the air, making identification more confusing [12]. As such, species were identified underwater itself and compared to [5-7,12]. The absence of an orange ring near the periproctal cone projection, the presence of blue lines of iridophores, white spots on the interambulacral areas and documentation from the Mauritius Oceanographic Institute confirmed the identity of the sample as Diadema savignyi (Fig. 1).

\subsection{Sample Extraction}

Table 1 shows that methanolic shell extracts gave higher extraction yield if compared to methanolic gonadal extract. However, if the drying methods are compared, not using the FD process seems to be a better option. Secondary metabolites are normally not subjected to degradation when FD is employed although the contrary was observed in this study. This conforms to what have been stated by [13] and [14] that FD has different impacts on different samples. The extreme vacuum applied during the FD process might have caused the important loss of volatile and sensitive compounds, hence, explaining the low yield of FD samples. Most of the bioactive compounds extracted from both shells and gonads must have had a polarity index close to that of methanol, 5.1.

\subsection{Total Phenols}

Both volatile bioactives and polyphenols concentrations are known to vary when samples are freeze-dried [13]. The results from Fig. 2 are coherent to what has been reported by [13]. Indeed, NFD samples gave higher phenolic content; $420 \mathrm{mg} \mathrm{GAE} / \mathrm{g}$ DW and $688.1 \mathrm{mg} \mathrm{GAE} / \mathrm{g} \mathrm{DW}$ for NFD methanolic shell and gonadal extract, respectively. However, they are in disagreement to what was hypothesized; FD methanolic extract would yield higher phenolic content as it restricts biological activity. The high vacuum system employed during the FD process might explain the subsequent phenolic compound degradation. According to [15], the sea urchin diet can affect the gonadal biochemical composition. This may probably explain why gonadal extract yielded higher phenolic content.

\subsection{Antibacterial Bioassay}

\subsubsection{Shell extract}

The Kruskal-Wallis $\mathrm{H}$ test revealed no significant difference on a comparison of the drying methods and inhibitory activity $(P>0.05)$. The high potency of the shell extract can be explained by the presence of the PHNQs, more specifically echinochrome A. According to [4], echinochrome A has an inhibitory effect on both Gram-positive and Gram-negative bacteria by disturbing the bacterial metabolism.

\subsubsection{Gonadal extract}

Similar to the shells, the gonads are also made up of echinochrome A and carotenoids [15]. This may possibly explain its inhibitory effect on the strains.

Table 1: Average yield (\%) for both shells and gonadal extracts.

\begin{tabular}{lccccc} 
State & \multicolumn{2}{c}{ Shells } & & \multicolumn{2}{c}{ Gonads } \\
\cline { 2 - 3 } \cline { 5 - 6 } & Methanol & Chloroform & & Methanol & Chloroform \\
NFD & $9.13 \pm 0.87$ & $3.58 \pm 0.92$ & & $8.23 \pm 0.92$ & $2.28 \pm 0.76$ \\
FD & $5.42 \pm 0.56$ & $3.08 \pm 0.64$ & & $7.22 \pm 0.46$ & $6.72 \pm 0.27$ \\
Interaction & $P$ & & & \\
Between state & 0.093 & & 0.003 & \\
* solvent & & & & \\
\hline
\end{tabular}

FD: Freeze-drying, NFD: Nonfreeze-drying 
In the current study, Gram-negative bacteria E. coli $(16.3 \pm 1.37 \mathrm{~mm})$ and Gram-positive bacteria $S$. aureus $(17.1 \pm 0.23 \mathrm{~mm})$ proved to be highly sensitive when NFD methanolic shell extract and FD methanolic gonadal extract were employed, respectively (Tables $2 \& 3$ ). This implies that FD gonadal extract conserved specific antibacterial bioactives while using NFD shell extracts conserved freeze-dried sensitive compounds.

Strong positive correlation between the TPC and antibacterial activity of $S$. aureus was obtained using both FD gonadal chloroform

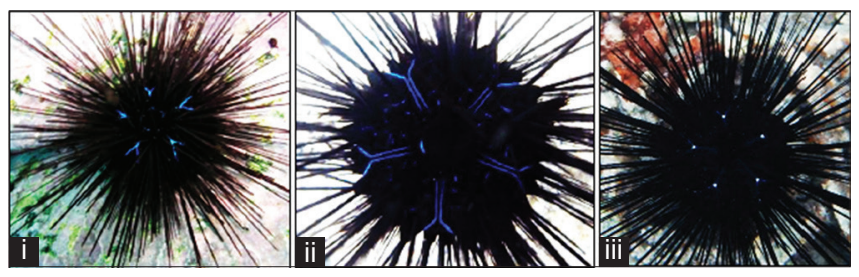

Fig. 1: Comparing the length ratio of the central axis of the Y-shaped structure to the V-component (i) Diadema sp. (ii) Diadema savignyi (iii) sample [12].

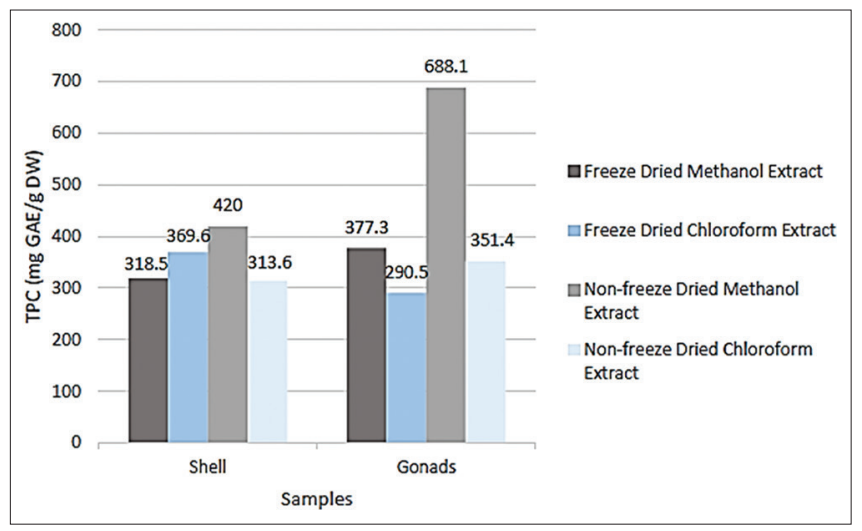

Fig. 2: Total phenolic content of samples. and non-FD methanolic shell extract. This implies that as the phenolic content increases so does the antibacterial activity. E. coli and $S$. aureus were the most vulnerable strains using both the shell and gonadal extracts, respectively, reporting both an MIC value of $6.25 \mu \mathrm{g} / \mathrm{ml}$. While Enterococcus spp. and Acinetobacter spp. were the least sensitive strains with MIC value of $12.5 \mu \mathrm{g} / \mathrm{ml}$ and $25 \mu \mathrm{g} /$ $\mathrm{ml}$ correspondingly.

Compared to [1] who worked with Diadema setosum, higher MIC value was obtained for $S$. aureus suggesting that $D$. savignyi being more competitive than $D$. setosum exerts a potential antimicrobial effect. MBC was also performed, and the extracts were found to have a bacteriostatic effect.

\subsection{Antioxidant Assay}

\subsubsection{Shell extract}

The NFD methanolic shell extract had slightly higher antioxidant activity compared to the standard, with an $\mathrm{IC}_{50}$ of $3.77 \mu \mathrm{g} / \mathrm{ml}$. Similar results were obtained by [16], suggesting that PHNQ pigments are highly concentrated in the shells. This was confirmed by the orange to the brown-like color of the extracts. In the current study, a concentration of $30 \mu \mathrm{g} / \mathrm{ml}$ yielded $97.6 \%$ (Fig. 3) inhibition exceeding that of the control, $96.1 \%$. This suggests that NFD methanolic shell extract has a strong antioxidant potential similar to that of the pure compound, ascorbic acid. A statistically strong significant correlation was obtained for the NFD methanolic shell extract, explaining that phenolic compounds are responsible for the scavenging activity. These results are in line to [17], PHNQ highly resembles the polyphenolic components.

\subsubsection{Gonadal extract}

Compared to the shell extracts, no gonadal extracts had an antioxidant capacity as good as the positive control, ascorbic acid. Among the two solvents, $\mathrm{FD}$ methanolic extracts yielded high activity with an $\mathrm{IC}_{50}$ of $6.11 \mu \mathrm{g} / \mathrm{ml}$ close to that of ascorbic acid $5.60 \mu \mathrm{g} / \mathrm{ml}$ (Fig. 4). Gonads are generally known to contain high antioxidant capacity as they are made up of both carotenoids and echinochrome A [15]. In addition to the high solubility of echinochrome A in a polar solvent, the presence

Table 2: Zone of inhibition (in $\mathrm{mm}$ ) using the shell extract.

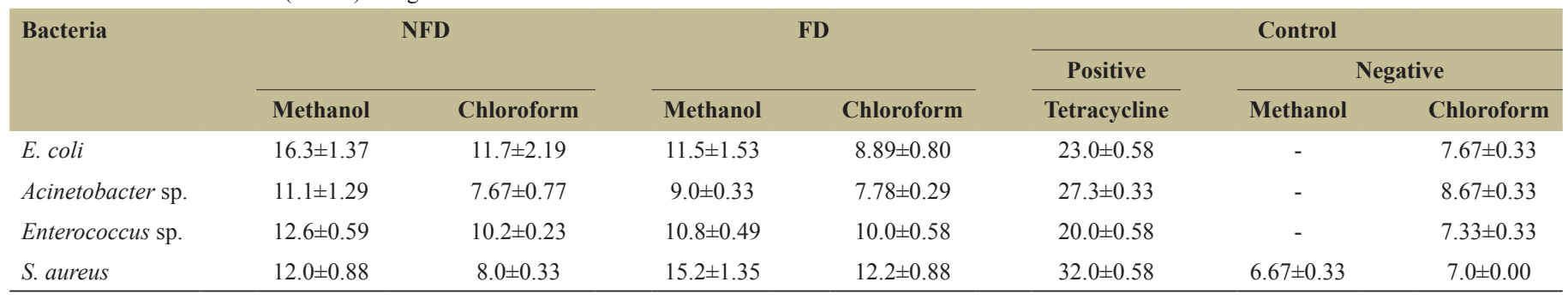

E. coli: Escherichia coli, S. aureus: Staphylococcus aureus, FD: Freeze-drying, NFD: Nonfreeze-drying

Table 3: Zone of inhibition (in $\mathrm{mm}$ ) using gonadal extract.

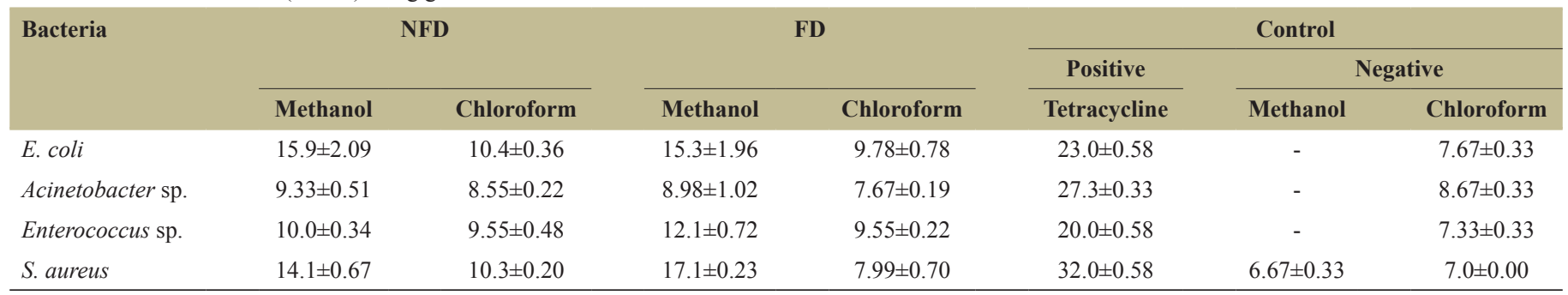

E. coli: Escherichia coli, S. aureus: Staphylococcus aureus, FD: Freeze-drying, NFD: Nonfreeze-drying 


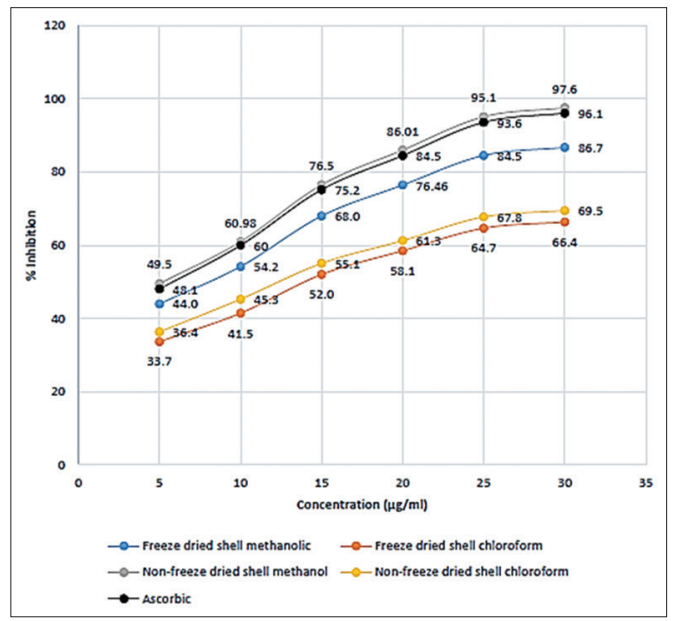

Fig. 3: Scavenging effects of shell tissue and standard ascorbic acid.

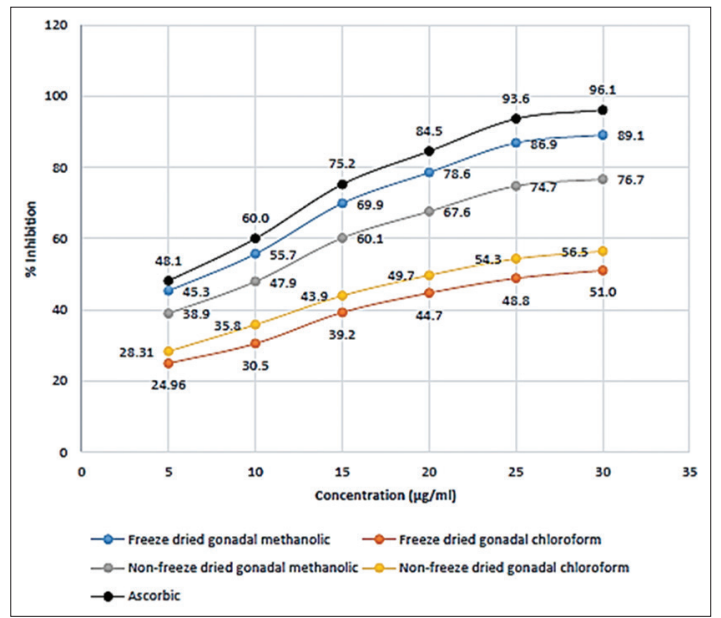

Fig. 4: Scavenging effects of gonadal tissue and standard ascorbic acid.

of an $\mathrm{OH}$ group at the $2^{\text {nd }}, 3^{\text {rd }}$, and $7^{\text {th }}$ positions of the molecule increases its scavenging capacity [18]. The difference in results can be a consequence of substitution with other molecules such as methoxy, methyl acetate, or amino [17].

Low activity was recorded for both the shell and gonadal chloroform extracts. Non-PHNQ components could be among the many bioactives extracted explaining these poor results.

Concerning the impact of the drying methods, FD methanolic extract seems to increase the antioxidant capacity of gonads but using FD sample appears to be a better option when chloroform is used as a solvent.

\subsection{Larvicidal Activity}

Fig. 5 demonstrates that methanolic extracts had higher larvicidal activity as compared to the chloroform extract. This implies that the larvicidal bioactives had a polarity index close to that of methanol. FD methanolic gonadal extract gave a lower $\mathrm{IC}_{50}, 1.381 \%$ suggesting its effectiveness. FD process must have protected sensitive compounds responsible for the larvicidal activity. The high TPC levels recorded in gonads (377.3 mg GAE/g DW) could be responsible for the larvicidal activity of FD methanolic gonadal extract. Anyhow, FD extract must have had other unknown secondary metabolites acting in synergy to

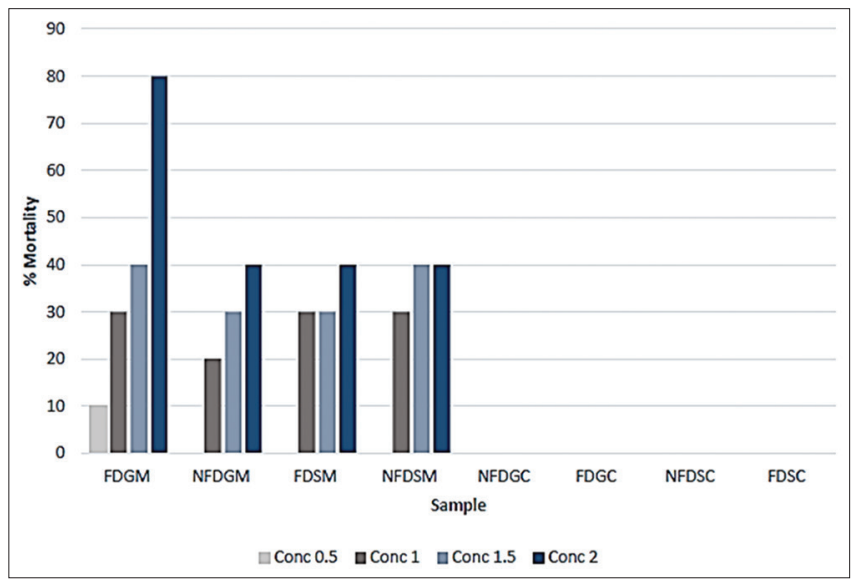

Fig. 5: Larvicidal activity of the different extracts.

yield such a high larvicidal property $\left(\mathrm{IC}_{50} 1.381 \%\right)$. Comparison of the larvicidal activity of both the shells and gonads suggest that the gonads contain important larvicidal compounds.

The correlation between the TPC and larvicidal activity yielded positive correlation for the NFD sample and negative correlation for the FD sample. This meant that the larvicidal activity is directly proportional to the NFD sample but inversely proportional to the FD sample. Other than phenolic compound, the larvicidal activity can be correlated to other unknown components.

\section{CONCLUSION}

The choice of drying methods and solvents used proved to be a crucial step as it eventually influenced the bioassay results. Methanol turned out to be the best solvent to remove the maximum amount of bioactive components due to its high polarity index of 5.1. The non-FD process conserved the highest amount of secondary metabolites for both the shells and gonads, displaying an extraction yield of $9.13 \%$ and $7.22 \%$, respectively. The antimicrobial assay results demonstrate that both the shell and gonadal extracts are a potential source of novel antimicrobial drugs. The pigments found in the shells have potential scavenging ability better than ascorbic acid and could be used as natural foodgrade antioxidant. The larvicidal activity exerted by Diadema urchins were low compared to known organism exhibiting larvicidal activity such as the sea cucumbers.

\section{REFERENCES}

1. Marimuthu K, Gunaselvam P, Rahman MA, Xavier R, Arockiaraj J, Subramanian $\mathrm{S}$, et al. Antibacterial activity of ovary extract from sea urchin Diadema setosum. Eur Rev Med Pharmacol Sci 2015;19:1895-9.

2. Ebert TA, Southon JR. Red sea urchins (Strongylocentrotus franciscanus) can live over 100 years: Confirmation with A-bomb ${ }^{14}$ carbon. Fishery Bull 2003;101:915-22.

3. Powell C, Hughes AD, Kelly MS, Conner S, McDougall GJ. Extraction and identification of antioxidant polyhydroxynaphthoquinone pigments from the sea urchin, Psammechinus miliaris. LWT Food Sci Technol 2014;59:455-60.

4. Service M, Wardlaw AC. Echinochrome-A as a bactericidal substance in the coelomic fluid of Echinus esculentus (L.). Comp. Biochem Physiol 1984;79B:161-5.

5. Coppard SE, Campbell AC. Taxonomic significance of spine morphology in the echinoid genera Diadema and Echinothrix. Invert 
Biol 2005;123:357-71.

6. Coppard SE, Campbell AC. Taxonomic significance of test morphology in the echinoid genera Diadema gray, 1825 and Echinothrix peters, 1853 (Echinodermata). Zoosystema 2006;28:93-112.

7. Rodriguez A, Hernandez JC, Clemente S, Coppard SE. A new species of Diadema (Echinodermata: Echinoidea: Diadematidae) from the eastern Atlantic Ocean and a neotype designation of Diadema antillarum (Philippi, 1845). Zootaxa 2013;3636:144-70.

8. Shamsuddin LH, Kumari GM, Noraznawati I. Antibacterial activity of three species of sea urchin extracts from Pulau Bidong, Terengganu. Sustain Sci Manage 2010;5:116-24.

9. Eloff JN. A sensitive and quick microplate method to determine the minimal inhibitory concentration of plant extracts for bacteria. Planta Med 1998;64:711-3.

10. Shankarlal S, Prabu K, Natarajan E. Antimicrobial and antioxidant activity of purple sea urchin shell (Salmacis virgulata L. Agassiz and Desor 1846). Am Eurasian J Sci Res 2011;63:178-81.

11. Dhinakaran ID, Lipton AP. Studies on the bioactivity of Holothuria atra extracts collected from the South east coast of India. Int J Biol Biol Sci 2014;3:6-11.

12. Chow S, Kajigaya Y, Kuroji H, Niwa K, Shibuno T, Nanami A, et al. On the fourth Diadema Species (Diadema-sp) from Japan. PLoS ONE 2014;9:1-9.

13. Oikawa A, Otsuka T, Jikumaru Y, Yamaguchi S, Matsuda F,
Nakabayashi R, et al. Effects of freeze-drying of samples on metabolite levels in metabolome analyses. J Sep Sci 2011;34:3561-7.

14. Abascal K, Ganora L, Yarnell E. The effect of freeze-drying and its implications for botanical medicine: A review. Phytother Res 2005; $19: 655-60$.

15. Archana A, Babu RK. Nutrient composition and antioxidant activity of gonads of sea urchin Stomopneustes variolaris. Food Chem 2016;197:597-602.

16. Kuwahara R, Hatate H, Chikami A, Murata H, Kijidani Y. Quantitative separation of antioxidant pigments in purple sea urchin shells using a reversed-phase high performance liquid chromatography. LWT Food Sci Technol 2010;43:1185-90.

17. Zhou DY, Qin L, Zhu BW, Wang XD, Tan H, Yang JF, et al. Extraction and antioxidant property of polyhydroxylated naphthoquinone pigments from spines of purple sea urchin Strongylocentrotus nudus. Food Chem 2011;129:1591-7.

18. Popov AM, Krivoshapko ON. Protective effects of polar lipids and redox-active compounds from marine organisms at modeling of hyperlipidemia and diabetes. J Biomed Sci Eng 2013;6:543-50.

How to cite this article:

Tee LKY, Puchooa D, Bhoyroo V. Bioactive potential of Diadema sp. from the South East coast of Mauritius. J App Biol Biotech. 2017;5(6):9-13. DOI: 10.7324/JABB.2017.50602 